\title{
الجناس للكلمة ساعة في القرآن الكريم التي قبلها حرف
}

\section{Eka Septya Nailus S ${ }^{1}$, Mundzar Fahman², Miftahul Mufid ${ }^{3}$}

Institut Agama Islam Sunan Giri Bojonegoro

Email: $\underline{\text { mahman2002@yahoo.com, miftahul.mufid@gmail.com }}$

المستخلص: "الجناس هو نوع من الدراسة البلاغية و التى يكون التحسين بها راجعا الى اللفظ. هذا البحث يبحث عن الجناس للكلمة "ساعة" في القرآن الكريم. لانّ تلك الكلمة تشتمل المميزات، قد وجدت الباحثة الكلمة "ساعة" في أربعة عشرين أماكن فقط في القرآن الكريم وفقا لعدد الساعات في يوم واحد ليلة واحدة أي گr ساعة. وأدواته البحث هي الملاحظة والوثائقية. ومصادر البيانات هي القرآن الكريم و كتب بلاغة و كتب تفسير التي تتعلق به. اما نتائج البحث لهذا البحث هي المعنى والفائدة للكلمة "ساعة" في القرآن الكريم هو بمعنيان، المعنى الاول بمعنى "القيامة" موجود في

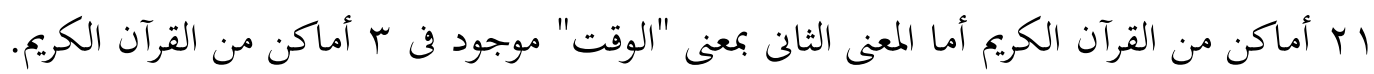
وأسلوب الجناس للكلمة "ساعة" في القرسن الكريم هو الجناس التام (محاثل) لان كلمتين المتجانسين من نوع واحد فعل و فعل."

كلمة رائيسية : الجناس، الساعة، القرآن، درسة بلاغية

المقدمة

حاول كثير من علماء اللسانيات و في عهود مختلفة، صياغة تعريف جامع مانع اللغة، وكان من أوائل من قدّم تعريفا ذكيا اللغة هو أبو الفتح عثمان بن جنّى من علماء القرن الرابع الهجرى. فقد جاء في كتابه الخصائص اللغة هي يعبر بها كلّ قوم عن أغراضطم. ثم عرفها ابن خلدون فن مقدمته حيث قال: اللغة في المتعارف هي عبارة المتكلم عن مقصوده. ثم جاء علماء اللغة الغربيون في العصر الحديث هو ابن جنّي منذ القرن الرابع الهجرى، حيث يعرفها سابير بأها ((وسيلة إنسانية مضة لإيصال الأفكار والعواطف والرغبات عن طريق نظام من الاشارات (المقصودة).(1)

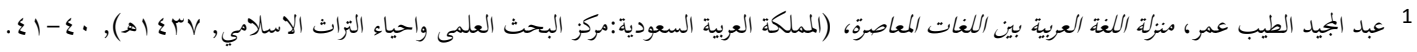


امّا اللغةُ العربية هي لغة مصطلحاتُ ومرادفاتُ التي دوّها العلماءُ في المعاجم. أمّا اصطلاحاً فهي إحدى لغاتِ العالم السامية والمنتشرة فى دائرة واسعة حول العالم، حيث إنّ هناك ب بع مليون من متحدّثيها، ويتركز بشكل كبير في الوطن العربي، وبعض المناطق المجاورة، مثل: تركيا، والأحواز، والسنغال، وتشاد، وإثيوبيا، وإيران، وجنوب السودان، وغيرهم من المناطق .اللغة العربيّة لغة مهمّ عند المسلمين. حيثُ لا تقْبَلُ العباداتُ المختلفة إلا بها، كما أنّ القرآن الكريم نزلَ بها. وفى هذا البحث، أرادت الباحثة أن تأخذ الكلمة "ساعة" التى قبلها حرف. لانّ تلك الكلمة تشتمل المميزات، الاول قد وجدت الباحثة الكلمة "ساعة" في أربعة عشرين أمكان فقط في القرآن الكريم وفقا لعدد

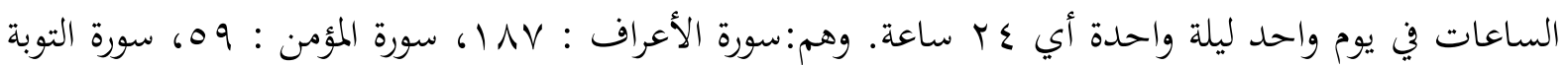

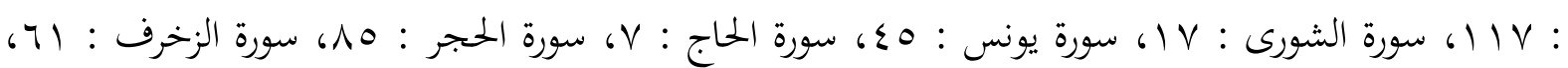

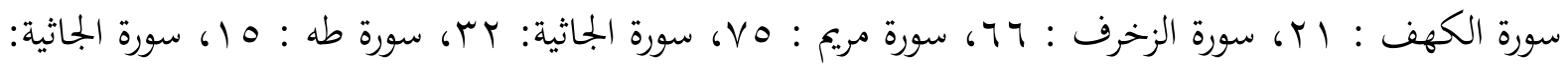

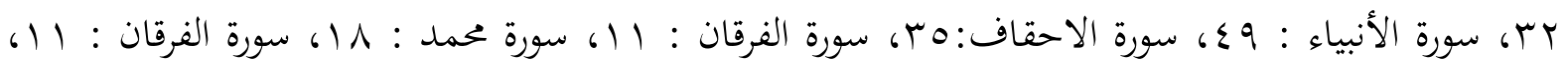

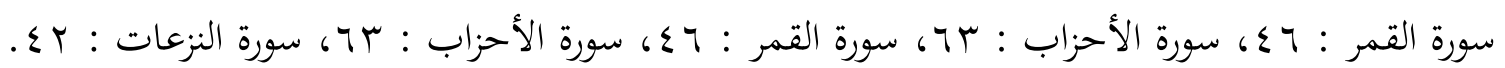
امّا الثانى هو الكلمة "ساعة" ككلمة المعرّب في لغة الاندونيسي بمعنى (saat)، و هذه الحجة جعلت الباحثة مهتم بهذه الكلمة. كان في القرآن الكريم: في سورة الاعراف:1 ا فن هذه السورة الكلمة "ساعة" بمعنى الوقت، ولكن في سورة التّوبة: ل 1 ا الكلمة "ساعة" بمعنى يوم القيامة. و أخذت الباحثة القرآن كأهداف البحث لأنّ فن القرآن وجد كثير المادة عن الجناس، بهذا البحث الباحثة ستحلّل عن الجناس للكلمة "ساعة" في القرآن الكريم، حتى تعرف الباحثة عن المعنى والفائدة عن كلمة "ساعة" في القرآن الكريم. لأن كثير من المزايا و فوائد في علم البلاغة.

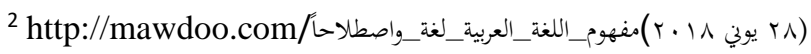




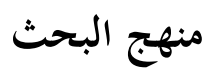

إنّ منهجية البحث هي طريقة العلمية للحصول على بيانات لغرض فائدة معيّنة.ّ في هذه

الدراسة هناك نوعان من الأجسام، وهما الأجسام الرسمية والأشياء المادية. والأشياء المادية هي السورة التي تشتمل الكلمة "ساعة"، و أن أجسامهم الرسمية هي الجناس في القرآن الكريم.

إنّ هذه الدراسة هي دراسة كيفية بالطريقة الوصفية والمكتبية. لأن الكيفية هي منهج البحث

الذى لا يحتاج إلى تصميم فروض البحث ولا تستعمل الباحثة الرقم في التفسير عن الإنتاج.

يتم إجراء هذا البحث ثلاث مراحل هي جمع البيانات وتحليل البيانات و التعريج لنتائج تحليل البيانات.

الكلمة "ساعة" في القرآن الكريم التي قبلها حرف

إن كلمة "ساعة" التي قبلها حرف جر جملتها ثمانية أماكن من القرآن الكريم وهي كما يلي:

أ) سورة الأعراف:1 أ

(يسألونك عن الساعة أيان مرساها) أي يسألونك أيها الرسول عن الساعة يقولون متى أرساؤها واستقرارها،

والسائلون هم قريش لأن السورة مكية ولم يكن في مكة أحد من اليهود، وسؤاهم عن هذا الوقت استبعاد

منهم لوقوعه وتكذيب بوجوده كما جاء حكاية عنهم: ((وَيَقُوْلُوْنَ مَتَى هذَا الْوَعْدُ إِنْ كُنْتُمْ صَادِقِينَْ)).

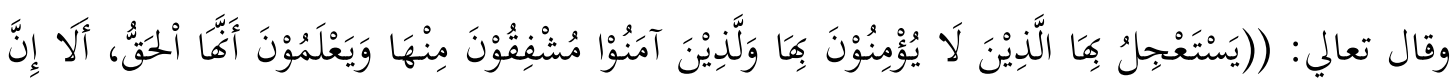

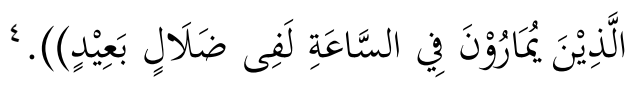

${ }^{3}$ Sugiono, Metode Penelitian Pendidikan : Pendekatan Kuantitatif Kualitatif, dan R\&D, (Bandung : Alfabeta, 2009)p.3

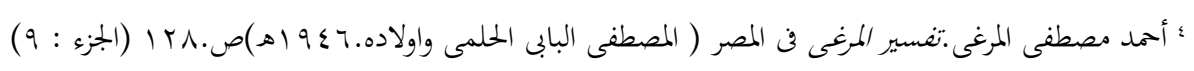


من هذا التفسير وهو التفسير المراغى حللت و ترجمت الباحثة من جهاد سياق جملة عن هذه كلمة "ساعة" معناها "القيامة" لان منظور من هذه الكلمة "متى أرساؤها واستقرارها"و تأكيد بذه الآية قال تعالي:

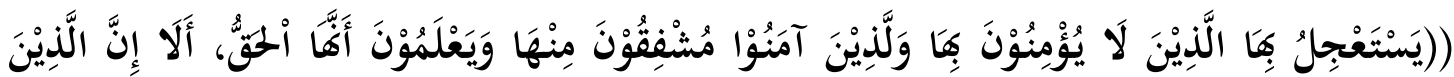
يُمَارُوْنَ فِي السَّاعَةِ لَفِى ضََلَالِ بَعِيْدِ().

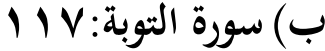

(الذين اتبعوه فن ساعة العسرة) أى الذي اتبعوه ولم يتخلفوا عنه وقت الشدة والضيف، وكانن عسرة في الزاد إذ كان الوقت فاية فصل الصيف الذي نفدت فيه مئونتهم من التمر وأول فصل الخريف الذي بدأ فيه إرطاب المسم الجديد ولا يمكن حمل شيء منه، فكان يكتفي الواحد منهم أو الإثنان بالتمرة الواحدة من التمر القديم ومنه المدور واليابس، ومنهم من تزود بالشعير المسوس والإهالة (الشحم المذاب) الزخخة المتغيرة الرانحة - وعسرة فن الماء حتى كانوا ينحرون البعير على قلة الرواحل ليعتصروا الفرث الذي في كرشه يبلوا به ألسنتهم-وعسرة فن الظهر (فن الإبل) حتى كان العشرة يعتقبون بعيرا واحدا-وعسرة فن الزمن إذكان في حرارة القيظ (شدة الحر) قال جابر بن عبد الله رضي الله عنه فن الساعة العسرة:عسرة الزاد وعسرة الماء، وقال ابن عباس لعمر رضي الله عنهم: حدثنا من شأن ساعة العسرة، فقال: خرجنا مع رسول الله صلى الله عليه وسلم ألى تبوك في قيظ شديد فنزلنا منزلا فأصابنا فيه عطش شديد حتى ظننا أن رقابنا ستنقطع حتي إن كان الرجال لينحر بعيره ليعصر فرثه فيشربه ويجعل ما بقى على كيده، فقال ابو بكر الصديق رضي الله عنه: يارسول الله إن الله قد عودك فن الدعاء خيرا فادعاء لنا،فرفع يديه فلم يرجعها حتى سالت السماء فأهطلت ثم سكنت فملئوا مامعهم ثم ذهبنا تنظر فلم نجدها جاوزت العسكر. 
من هذا التفسير وهو التفسير المراغى حللت و ترجمت الباحثة من جهاد سياق جملة عن هذه كلمة "ساعة"

معناها "الوقت" لان منظور من هذه الكلمة "أى الذي اتبعوه ولم يتخلفوا عنه وقت الشدة والضيف".

إذن من التحليل المقدم، كلمة "ساعة" من هذه الأية بمعنى "الوقت" لا بمعنى "القيامة".

$$
\text { ج) سورة الأنبياء:9 ( ج ع }
$$

((وهم من الساعة مشفقون)) أى وهم من عذاب يوم القيامة وسائر أحوالها خائفون وجلون.؟

من هذا التفسير وهو التفسير المراغى حللت و ترجمت الباحثة من جهاد سياق جملة عن هذه كلمة "ساعة"

معناها "القيامة" لان منظور من هذه الكلمة " أى وهم من عذاب يوم القيامة وسائر أحوالها خائفون

وجلون".

إذن من التحليل المقدم، كلمة "ساعة" من هذه الأية بمعنى "القيامة" لا بمعنى "الوقت".

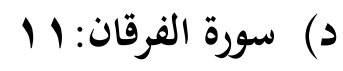

((بل كذبوا بالساعة)( أى ما أنكر هؤلاء المشركون ما جئنهم به من الحق، وتقولوا عليك ما تقولوا، إلا من

$$
\text { قبل أفم لايقنون بالبعث، ولا يصدقون بالثواب والعقاب. }
$$

والخلاصة إفم أتوا بأعجب من هذا كله وهو تكذيبهم بالساعة، ومن ذالك لاينتفعون بالدلائل ولا يتأملون

$$
\text { فيها. }
$$

من هذا التفسير وهو التفسير المراغى حللت و ترجمت الباحثة من جهاد سياق جملة عن هذه كلمة "ساعة"

معناها "القيامة" لان منظور من هذه الكلمة "أى ما أنكر هؤلاء المشركون ما جئنهم به من الحقى

وتقولوا عليك ما تقولوا، إلا من قبل أفم لايقنون بالبعث ".

$$
\begin{aligned}
& \text { " أحمد مصطفى المرغى.تفسير المرغى.ص. إ (الجزء : IV). }
\end{aligned}
$$

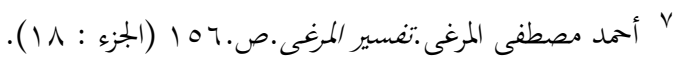


إذن من التحليل المقدم، كلمة "ساعة" من هذه الأية بمعنى "القيامة" لا بمعنى "الوقت".

$$
\text { ه) سورة الأحزاب:س }
$$

((يسألونك الناس عن الساعة)) أى يكثر الناس هذا السؤال، متى تقوم الساعة؟ فالمشرمون يسألون عن

ذالك استعجالا لها على طريق الهكم والاستهزاء. والمنافقون يسألون سؤال المتعنت العالم بما يجيب به

الرسول واليهود يسألون سؤال إمتحان واختبار، ليعلموا أيجيب بمثل ما في التورة من ردّ أمرها إلى الله أم

$$
\text { يجيب بشيء آخر؟ }
$$

من هذا التفسير وهو التفسير المراغى حللت و ترجمت الباحثة من جهاد سياق جملة عن هذه كلمة "ساعة" معناها "القيامة" لان منظور من هذه الكلمة "أى يكثر الناس هذا السؤال، متى تقوم الساعة؟ فالمشرمون يسألون عن ذالك استعجالا لما على طريق الهكم والاستهزاء". إذن من التحليل المقدم، كلمة "ساعة" من هذه الأية بمعنى "القيامة" لا بمعنى "الوقت". ز) سورة الزخرف: (1) (

(وإنه لعلم للساعة فلا تمترن بها واتبعون هذا صراط مستقيم) أى وإنّ القرآن يعلمكم بقيام الساعة ويخبركم وعنها وعن أهوالها. فلا تشكن فيها واتبعوا هداى، فهذا الذى أدوعكم إليه هو الصراط المستقيم الذي

$$
\text { لاعوج فيه وهو الموصل إلى الحق.? }
$$

من هذا التفسير وهو التفسير المراغى حللت و ترجمت الباحثة من جهاد سياق جملة عن هذه كلمة "ساعة" معناها "القيامة" لان منظور من هذه الكلمة "أى وإنّ القرآن يعلمكم بقيام الساعة ويخبركم وعنها

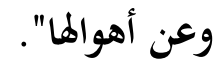

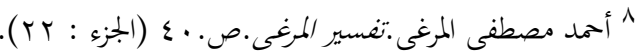

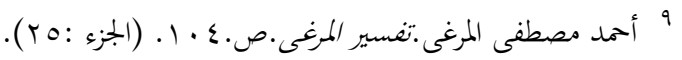


إذن من التحليل المقدم، كلمة "ساعة" من هذه الأية بمعنى "القيامة" لا بمعنى "الوقت".

$$
\text { ح) سورة النزعات: ع ع }
$$

(يسألونك عن الساعة أيان مرسها) أي يسألك أيها الرسول هؤلاء المكذبون بالبعث عن الساعة التي

$$
\text { تبعث فيها الموتى من قبورهم، متى قيامها وظهورها؟. }
$$

من هذا التفسير وهو التفسير المراغى حللت و ترجمت الباحثة من جهاد سياق جملة عن هذه كلمة "ساعة" معناها "القيامة" لان منظور من هذه الكلمة "أي يسألك أيها الرسول هؤلاء المكذبون بالبعث عن

الساعة التي تبعث فيها الموتى من قبورهم، متى قيامها وظهورها؟".

إذن من التحليل المقدم، كلمة "ساعة" من هذه الأية بمعنى "القيامة" لا بمعنى "الوقت".

تحليل الجناس للككلمة "ساعة" في القرآن الكريم

في هذا المبحث ، حللت الباحثة الجناس للكلمة "ساعة" في القرآن الكريم الذي بحثت قبله. ووجدت

الباحثة عن معنى كلمة "ساعة" وهي معنيان وهما ساعة بمعنى قيامة و ساعة بمعنى وقت. وجملة ساعة بمعنى قيامة هي احدى وعشرون كلمات، أما جملة ساعة بمعنى وقت هي ثلثة كلمات. وأسلوب الجناس للكلمة "ساعة" في هذا القرآن الكريم، ما يلي:

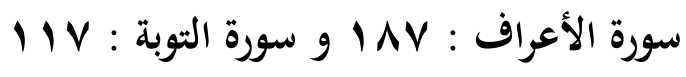

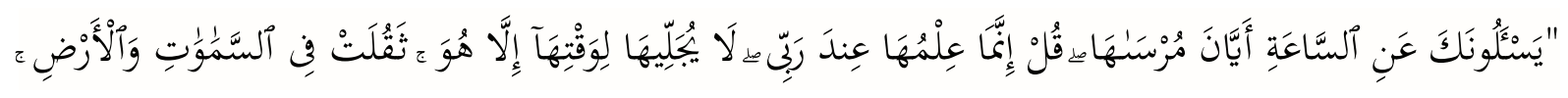

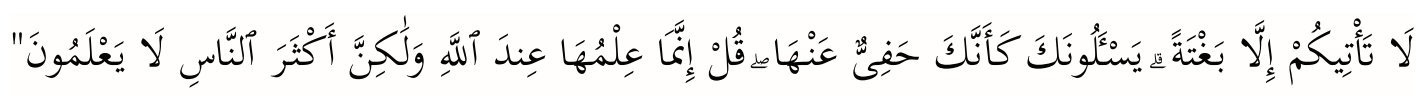

$$
10 \text { أحمد مصطفى المرغى.تغسير المرغى.ص.ب ب. (الجزء : .r). }
$$




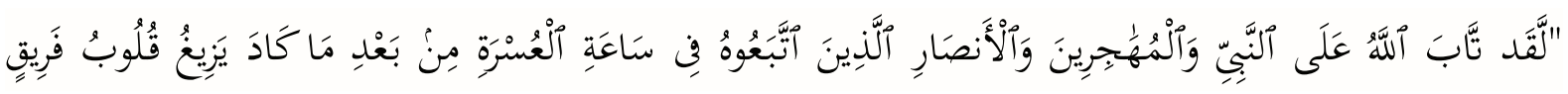

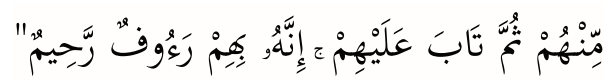
والجناس في هذه الآية بين "ساعة" و "ساعة" ويسمى بالجناس التام (تماثل) لأن كلمتين المتجانسين من نوع واحد

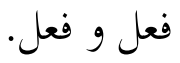

سورة الحجر : ه人 و سورة يونس : 0؟

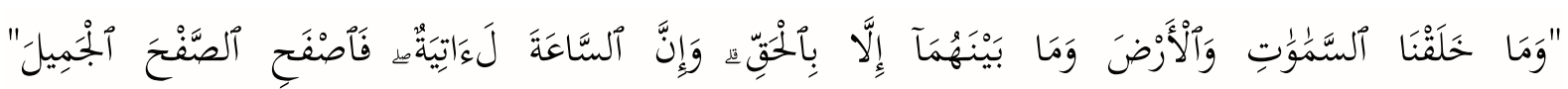

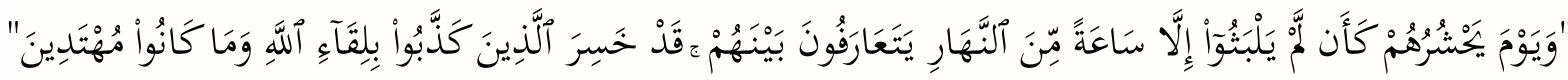
والجناس في هذه الآية بين "ساعة" و "ساعة" ويسمى بالجناس التام (مماثل) لأن كلمتين المتجانسين من نوع واحد

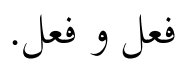

سورة الكهف : ا Y و سورة الاحقاف : P

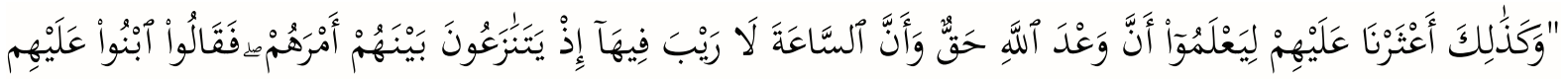

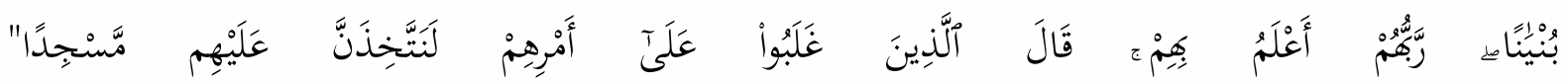

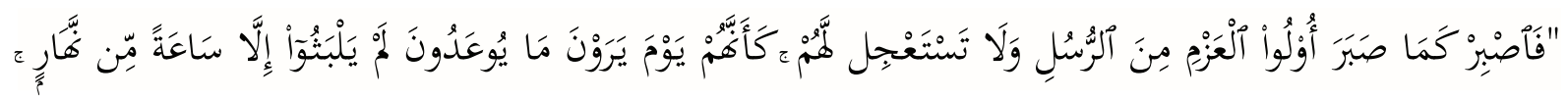

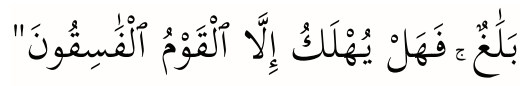
والجناس في هذه الآية بين "ساعة" و "ساعة" ويسمى بالجناس التام (نماثل) لأن كلمتين المتجانسين من نوع واحد

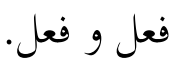
الحلاصة المعنى والفائدة للكلمة "ساعة" في القرآن الكريم هو بمعنيان، المعنى الاول بمعنى "القيامة" موجود فن إ أماكن من القرآن الكريم أما المعنى الثانى بمعنى "الوقت" موجود في ب أماكن من القرآن الكريم. 
والفائدة من السورة التي تشتمل كلمة ساعة هي: ساعة بمعنى قيامة: لمعرفة يوم القيامة وما حدث فيه، لمعرفة أنّ جميع الناس خائف من الذهول في يوم القيامة، لمعرفة كذب الكافرين في يوم القيامة، لمعرفة إنّ الله يأمر إلى رسوله أن يتحول إلى المشركين، و أنّ يوم القيامة هو وقت الاجتماع بين الناس وربه. ساعة بمعنى وقت: لمعرفة حرب تبوك وقبول التوبة من الله و معرفة عن تهديد المشركين شرح لفقدهم وإقامة قيامة بعد الموت. وأسلوب الجناس للكلمة "ساعة" في القربن الكريم هو الجناس التام (ماثيل) لان كلمتين المتجانسين من نوع واحد فعل و فعل. المراجع

- أحمد مصطفى المراغى، علوم البلاغة والبيان والمعانى والبليع،( دون المدينة: دار الكتب

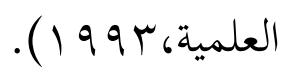

- أحمد مصطفى المرغى.تغسير المرغى فن المصر ( المصطفى البابى الحلمى واولاده.7 9 اهـ). - احمد مصطفي المراغي،علوم البلاغة، (لبنان: دار الكتاب العلمية، ب99 199 م.) - اسامة البحيرى، تيسر البلاغة، (كلية الادب جامعة طنطا، ج . . ب). - - إنعام الفوال عكاوى، المعجم المفصل فى علوم البلاغة البديع والمعانى والبيان. - - جلال الدين عبد الرحمن بن ابى بكر السيوطى، تغسير جلالين (دون المدينة: الحرمين جايا اندونيسيا، $\cdot(r \cdot \lambda$ - - حفنى ناصف، دروس البلاغة شمس البراعة، مكتبة المدينة، بـ 1 ا، باكستان. 
- حفني ناصف، محمد دياب سلطان محمد، مصطفى طموم، دووس البلاغة (باكستان: المدينة

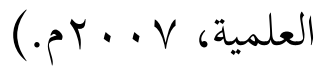

- الخطيب القزوينى، الإيضاح فى علوم البلاغة، (بيروت:دار الكتاب العلميت،دون السنة). حفنى

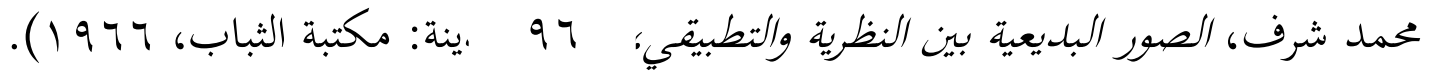

